\title{
Metal-Free Markovnikov-Type Alkyne Hydration under Mild Conditions
}

\author{
Wenbo Liu, Haining Wang, and Chao-Jun Li* \\ Department of Chemistry and FQRNT Center for Green Chemistry and Catalysis, McGill University, 801 Sherbrooke Street West, \\ Montreal, QC H3A 0B8, Canada
}

\section{Supporting Information}

ABSTRACT: A Markovnikov-type alkyne hydration protocol is presented using $20 \% \mathrm{CF}_{3} \mathrm{SO}_{3} \mathrm{H}(\mathrm{TfOH})$ as the catalyst under unprecedented mild conditions applicable to various alkynes, including terminal arylalkynes, terminal nonfunctionalized aliphatic alkynes, and internal alkynes with excellent regioselectivity in good to excellent yields (average yields $>85 \%)$. The reaction procedure operates under mild conditions $\left(25-70{ }^{\circ} \mathrm{C}\right)$, with broad functional group compatibility, and uses only slightly more than a stoichiometric amount of water in the absence of any transition metal. The success of this protocol hinges upon the utilization of trifluoroethanol as the solvent.

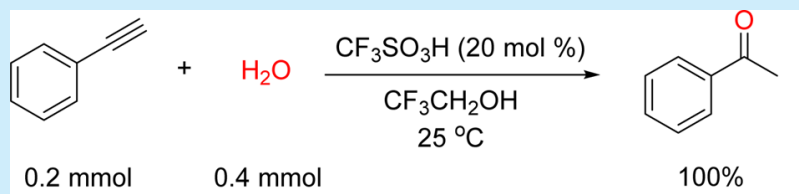

13 additional examples average yields $>85 \%$ onverting alkynes into carbonyl compounds through hydration, especially Markovnikov-type hydration (Scheme 1a), is a fundamental transformation in organic

Scheme 1. Comparison of Previous Work and This Work

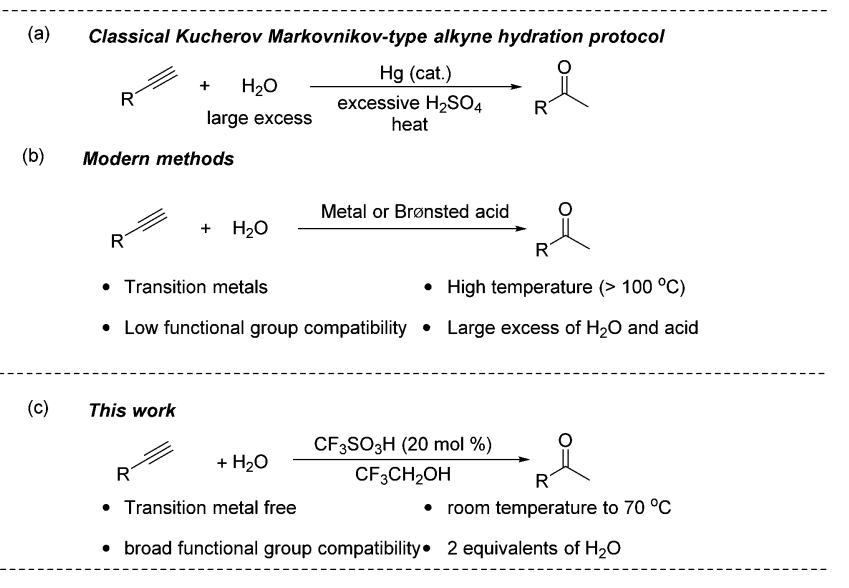

synthesis with $100 \%$ atom economy. ${ }^{1,2}$ Classical Kucherov procedures for alkynes' hydration into ketones employ mercuric salt as the catalyst in aqueous sulfuric acid. ${ }^{3,4}$ Due to the toxicity of $\mathrm{Hg}$ salts, many other metal-catalyzed alkyne hydration procedures have been developed, including ones catalyzed by $\mathrm{Ru},{ }^{5} \mathrm{Rh},{ }^{6} \mathrm{Pd},{ }^{7} \mathrm{Pt},{ }^{8,9} \mathrm{Sn}-\mathrm{W},{ }^{10} \mathrm{Au},{ }^{11-17} \mathrm{Fe},{ }^{18,19} \mathrm{Ir}^{20,21} \mathrm{Co},{ }^{22}$ $\mathrm{Ag}^{23,24}$ etc. Besides various metal catalysts, Brønsted-acidcatalyzed hydration reactions also exist in the literature. ${ }^{25,26}$ However, most of the reactions reported so far have suffered from at least one drawback: (1) high temperature $\left(>100{ }^{\circ} \mathrm{C}\right)$; (2) expensive noble metals ( $\mathrm{Ru}, \mathrm{Rh}, \mathrm{Pd}, \mathrm{Pt}, \mathrm{Au}, \mathrm{Ir}, \mathrm{Ag}$, etc.); (3) narrow functional group compatibility; (4) large excess of water and acidic additive besides the metal catalysts if any 


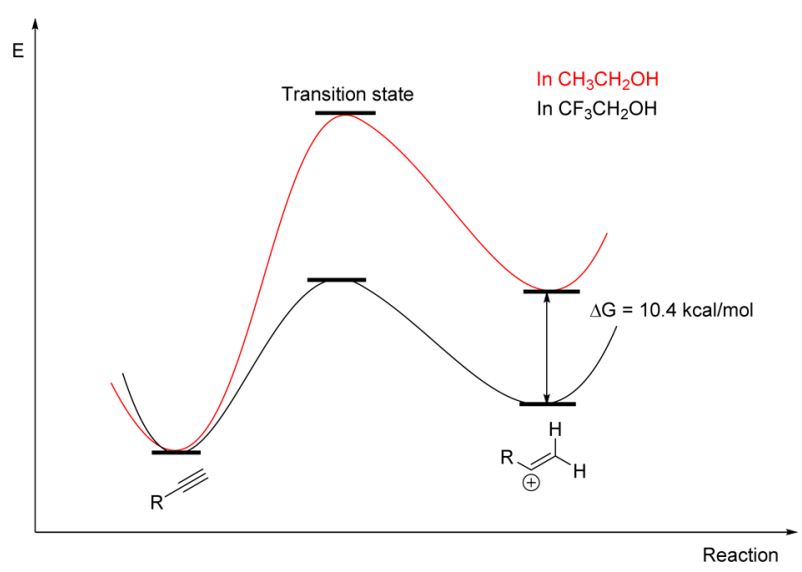

Figure 1. DFT calculation comparison on the protonation step of alkyne in TFE and ethanol.

rapidly found that the acidity of the Brønsted acid catalyst is crucial to the reaction efficiency after briefly screening common organic acids. With TFE as the solvent, $20 \mathrm{~mol} \%$ of $\mathrm{CH}_{3} \mathrm{CO}_{2} \mathrm{H}$ as the catalyst cannot produce any product (entry 1 in Table 1 ),

Table 1. Optimization of the Model Reaction

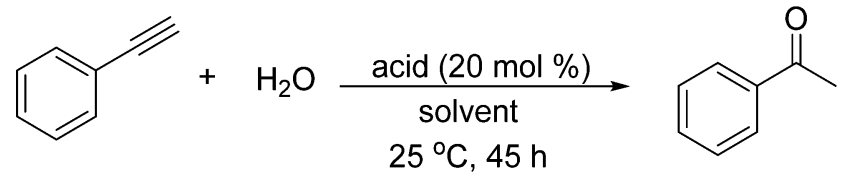

\begin{tabular}{|c|c|c|c|}
\hline entry $^{a}$ & solvent & acid catalyst & yield $(\%)^{b}$ \\
\hline 1 & $\mathrm{CF}_{3} \mathrm{CH}_{2} \mathrm{OH}$ & $\mathrm{CH}_{3} \mathrm{CO}_{2} \mathrm{H}$ & 0 \\
\hline 2 & $\mathrm{CF}_{3} \mathrm{CH}_{2} \mathrm{OH}$ & $\mathrm{CF}_{3} \mathrm{CO}_{2} \mathrm{H}$ & 3 \\
\hline 3 & $\mathrm{CF}_{3} \mathrm{CH}_{2} \mathrm{OH}$ & $\mathrm{CF}_{3} \mathrm{SO}_{3} \mathrm{H}$ & 100 \\
\hline 4 & cyclohexane & $\mathrm{CF}_{3} \mathrm{SO}_{3} \mathrm{H}$ & 3 \\
\hline 5 & $\mathrm{PhCl}$ & $\mathrm{CF}_{3} \mathrm{SO}_{3} \mathrm{H}$ & trace \\
\hline 6 & DMF & $\mathrm{CF}_{3} \mathrm{SO}_{3} \mathrm{H}$ & 0 \\
\hline 7 & DMSO & $\mathrm{CF}_{3} \mathrm{SO}_{3} \mathrm{H}$ & 0 \\
\hline 8 & $\mathrm{MeOH}$ & $\mathrm{CF}_{3} \mathrm{SO}_{3} \mathrm{H}$ & 0 \\
\hline 9 & THF & $\mathrm{CF}_{3} \mathrm{SO}_{3} \mathrm{H}$ & 0 \\
\hline 10 & DCE & $\mathrm{CF}_{3} \mathrm{SO}_{3} \mathrm{H}$ & 0 \\
\hline 11 & 1,4-dioxane & $\mathrm{CF}_{3} \mathrm{SO}_{3} \mathrm{H}$ & trace \\
\hline 12 & DCM & $\mathrm{CF}_{3} \mathrm{SO}_{3} \mathrm{H}$ & 5 \\
\hline 13 & $\mathrm{CHCl}_{3}$ & $\mathrm{CF}_{3} \mathrm{SO}_{3} \mathrm{H}$ & 3 \\
\hline 14 & $\mathrm{H}_{2} \mathrm{O}$ & $\mathrm{CF}_{3} \mathrm{SO}_{3} \mathrm{H}$ & 0 \\
\hline 15 & HFIP & $\mathrm{CF}_{3} \mathrm{SO}_{3} \mathrm{H}$ & 96 \\
\hline 16 & $\mathrm{CH}_{3} \mathrm{CN}$ & $\mathrm{CF}_{3} \mathrm{SO}_{3} \mathrm{H}$ & 0 \\
\hline 17 & $\mathrm{CH}_{3} \mathrm{CH}_{2} \mathrm{OH}$ & $\mathrm{CF}_{3} \mathrm{SO}_{3} \mathrm{H}$ & 0 \\
\hline 18 & $\mathrm{CH}_{3} \mathrm{CO}_{2} \mathrm{H}$ & $\mathrm{CF}_{3} \mathrm{SO}_{3} \mathrm{H}$ & trace \\
\hline
\end{tabular}

${ }^{a}$ Reaction conditions: phenylacetylene $(22 \mu \mathrm{L}, 0.2 \mathrm{mmol}), \mathrm{H}_{2} \mathrm{O}(8 \mu \mathrm{L}$, $0.4 \mathrm{mmol}, 2$ equiv), acid ( $0.04 \mathrm{mmol}, 0.2$ equiv), solvent $(1 \mathrm{~mL}), 25$ ${ }^{\circ} \mathrm{C}, 45 \mathrm{~h}$. ${ }^{b}$ Yield was determined by ${ }^{1} \mathrm{H}$ NMR analysis using $1,3,5-$ trimethoxybenzene as the internal standard.

whereas $\mathrm{CF}_{3} \mathrm{CO}_{2} \mathrm{H}$ could only deliver the product in $3 \%$ yield (entry 2). By choosing a stronger acid as the catalyst, we were pleased to find that $\mathrm{CF}_{3} \mathrm{SO}_{3} \mathrm{H}(20 \mathrm{~mol} \%)$ could give the desired product with a quantitative yield (entry 3 ). To further confirm the power of TFE in this reaction, we conducted control experiments using other common solvents, including protic organic solvents, aprotic polar solvents, aprotic nonpolar solvents, and water. Most solvents could not produce any hydration product (entries 6-10,14, 16, and 17), and some could only generate the product in very low yields $(<5 \%)$ if any (entries 4, 5, 11-13, and 18). Not unexpectedly, as the twin of TFE, hexafluoro-2-propanol (HFIP) could also generate the product in excellent yield (96\%), as efficiently as TFE (entry 15). However, considering the price difference of these two fluoro-containing solvents, we decided to employ TFE as the solvent to execute further investigations. Therefore, the "standard conditions" were set as as alkyne ( 1 equiv), $\mathrm{H}_{2} \mathrm{O}$ (2 equiv), $\mathrm{CF}_{3} \mathrm{SO}_{3} \mathrm{H}$ (0.2 equiv), and $\mathrm{CF}_{3} \mathrm{CH}_{2} \mathrm{OH}(1 \mathrm{~mL})$ at $25{ }^{\circ} \mathrm{C}$.

After confirming our hypothesis, we then examined the functional group compatibility by utilizing various arylalkynes 1 with different functional groups. Arylalkynes without strong electron-withdrawing groups (EWG) (2a, 2d, 2f, 2h, 2i, 2l) could generate the hydration products in excellent yields under the standard conditions (Scheme 2). With EWGs attached to the aromatic rings, a higher temperature (i.e., $70{ }^{\circ} \mathrm{C}$ ) was required $(\mathbf{2 b}, \mathbf{2 c}, 2 \mathrm{~g}, 2 \mathbf{j}, \mathbf{2 k}, \mathbf{2 m})$ to generate the desired hydration products with excellent yields. In contrast, a previously reported $\mathrm{TfOH}$-catalyzed alkyne hydration protocol in THF only produced $4 \%$ GC yield after $78 \mathrm{~h}$ at $100{ }^{\circ} \mathrm{C}$ when

Scheme 2. Scope of This Alkyne Hydration Reaction ${ }^{a}$
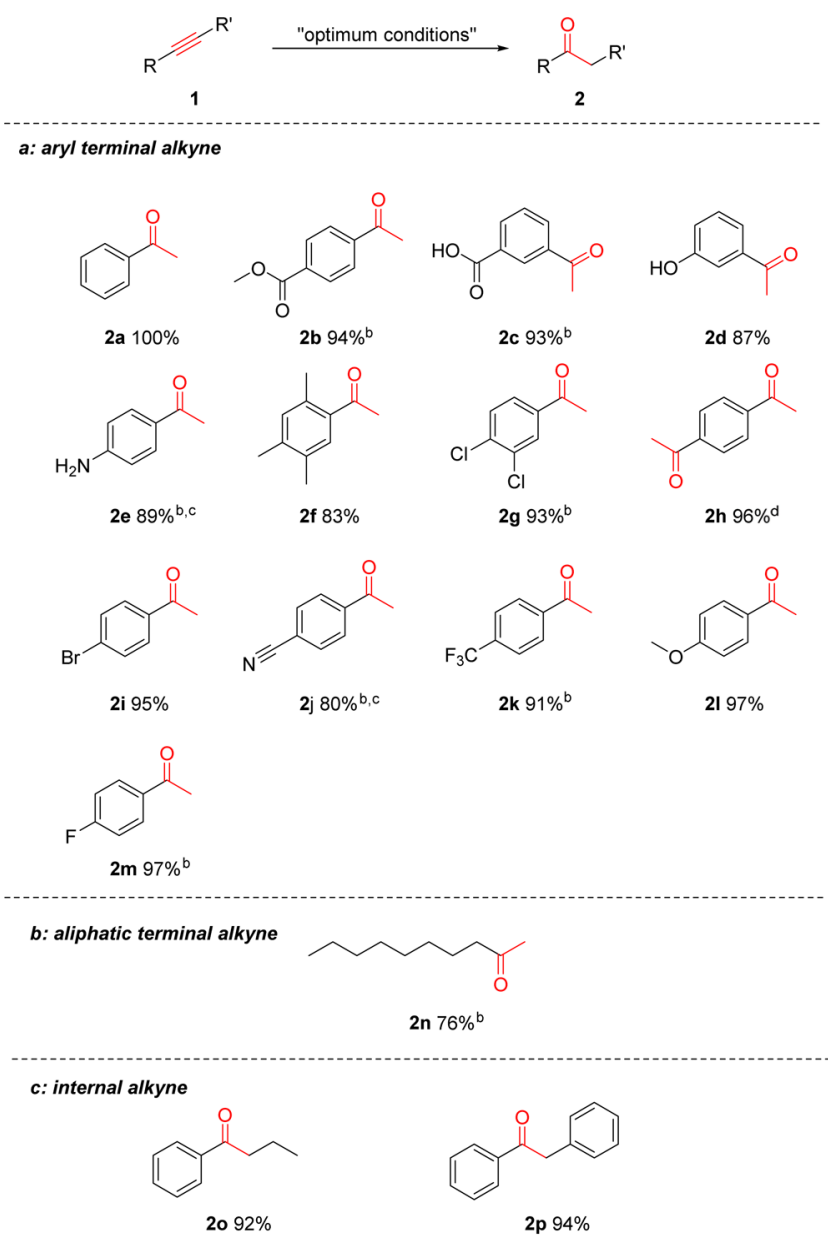

${ }^{a}$ Please refer to the supporting information for the reaction details including reaction time for each substrate. All the yields are isolated ones. ${ }^{b}$ Reaction conducted at $70{ }^{\circ} \mathrm{C}$. ${ }^{c}$ Acid ( 1.2 equiv) was added in the reaction system. ${ }^{d} 1,4$-Diethynylbenzene $(0.2 \mathrm{mmol}, 26 \mathrm{mg}), \mathrm{H}_{2} \mathrm{O}$ $(0.8 \mathrm{mmol}, 16 \mu \mathrm{L}), \mathrm{CF}_{3} \mathrm{SO}_{3} \mathrm{H}(0.08 \mathrm{mmol}, 8 \mu \mathrm{L}), \mathrm{CF}_{3} \mathrm{CH}_{2} \mathrm{OH}(1$ $\mathrm{mL}), 25{ }^{\circ} \mathrm{C}$. 
4-trifluoromethylphenylacetylene was used as the substrate. ${ }^{25}$ With basic reaction sites (such as $-\mathrm{NH}_{2}$ and $-\mathrm{CN}$ ) in the substrates $(2 \mathrm{e}, 2 \mathbf{j})$, apart from the $20 \%$ acid catalyst, another equivalent of acid was necessary to quench the basicity. Most organic functional groups, including ester $(\mathbf{2 b}),-\mathrm{CO}_{2} \mathrm{H}(\mathbf{2 c})$, $-\mathrm{OH}(\mathbf{2 d}),-\mathrm{NH}_{2}(\mathbf{2 e})$, alkyl group (2f), $-\mathrm{Cl}(\mathbf{2 g}),-\mathrm{Br}(\mathbf{2 i})$, $-\mathrm{CN}(2 \mathbf{j}),-\mathrm{CF}_{3}(\mathbf{2 k}),-\mathrm{OMe}(\mathbf{2 l})$, and $-\mathrm{F}(\mathbf{2 m})$, could survive the reaction conditions, and they all delivered the products in excellent yields $(80-100 \%)$. This broad functional group compatibility and mild conditions would provide enormous potential to further functionalize the hydration products, especially in complex natural product synthesis. Besides aryl alkynes, aliphatic alkyne can also deliver the Markovnikov-type hydration product with good yield (76\%), although a higher temperature $\left(70^{\circ} \mathrm{C}\right)$ was necessary $(\mathbf{2 n})$. Unfortunately, the protocol is not applicable to the functionalized aliphatic alkynes including propargylic alcohol and methyl propiolate. However, our reaction procedure is applicable to the internal arylalkynes $(\mathbf{2 o}, \mathbf{2 p}$ ) by using the standard conditions.

To further examine the synthetic potential of our protocol, we also conducted a gram scale reaction by choosing phenylacetylene $(1.4 \mathrm{~g}, 14 \mathrm{mmol}$ ) as the substrate (Scheme 3 ). Under our standard conditions, the desired hydration product acetophenone could be isolated at a 91\% yield, which confirms its suitability for large-scale reactions.

Scheme 3. Gram Scale Reaction under Our Standard Conditions
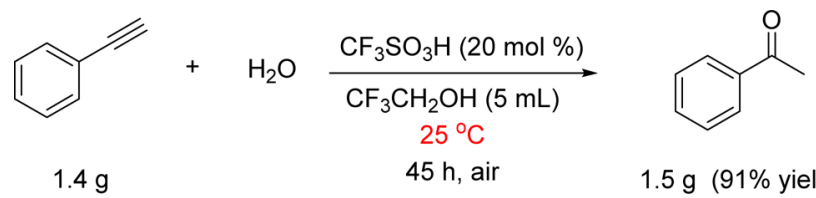

$1.5 \mathrm{~g}(91 \%$ yield $)$

In summary, we have developed an extremely mild protocol to accomplish alkyne hydration. Our reaction operates at low temperature with broad functional group compatibility, is applicable to various alkynes, and only requires slightly more than a stoichiometric amount of water in the absence of any transition metals. Moreover, the reaction conditions are also applicable for the large-scale reaction. The success of our reaction lies in the use of TFE as the solvent. Exploration of other nucleophiles to attack the vinyl carbocation is underway in our laboratory and will be reported in due course.

\section{ASSOCIATED CONTENT}

\section{S Supporting Information}

The Supporting Information is available free of charge on the ACS Publications website at DOI: 10.1021/acs.orglett.6b00801.

Experimental section, spectroscopic data, and ${ }^{1} \mathrm{H},{ }^{13} \mathrm{C}$, and ${ }^{19} \mathrm{~F}$ NMR spectra (PDF)

\section{AUTHOR INFORMATION}

\section{Corresponding Author}

*E-mail: cj.li@mcgill.ca.

\section{Notes}

The authors declare no competing financial interest.

\section{ACKNOWLEDGMENTS}

We are grateful to the Canada Research Chair (Tier 1) foundation, FQRNT (CCVC), CFI, and NSERC for their support of our research. W.L. is thankful for McGill Drug Development Training Program (DDTP) for a fellowship.

\section{REFERENCES}

(1) Hintermann, L.; Labonne, A. Synthesis 2007, 2007, 1121-1150.

(2) Li, C.-J.; Trost, B. M. Proc. Natl. Acad. Sci. U. S. A. 2008, 105, 13197-13202.

(3) Kutscheroff, M. Ber. Dtsch. Chem. Ges. 1884, 17, 13-29.

(4) Kutscheroff, M. Ber. Dtsch. Chem. Ges. 1881, 14, 1540-1542.

(5) Halpern, J.; James, B. R.; Kemp, A. L. W. J. Am. Chem. Soc. 1961, 83, 4097-4098.

(6) James, B. R.; Rempel, G. L. J. Am. Chem. Soc. 1969, 91, 863-865.

(7) Imi, K.; Imai, K.; Utimoto, K. Tetrahedron Lett. 1987, 28, 31273130.

(8) Baidossi, W.; Lahav, M.; Blum, J. J. Org. Chem. 1997, 62, 669672.

(9) Hartman, J. W.; Hiscox, W. C.; Jennings, P. W. J. Org. Chem. 1993, 58, 7613-7614.

(10) Jin, X.; Oishi, T.; Yamaguchi, K.; Mizuno, N. Chem. - Eur. J. 2011, 17, 1261-7.

(11) Fukuda, Y.; Utimoto, K. J. Org. Chem. 1991, 56, 3729-3731.

(12) Mizushima, E.; Sato, K.; Hayashi, T.; Tanaka, M. Angew. Chem., Int. Ed. 2002, 41, 4563-4565.

(13) Casado, R.; Contel, M.; Laguna, M.; Romero, P.; Sanz, S. J. Am. Chem. Soc. 2003, 125, 11925-11935.

(14) Leyva, A.; Corma, A. J. Org. Chem. 2009, 74, 2067-2074.

(15) Marion, N.; Ramón, R. S.; Nolan, S. P. J. Am. Chem. Soc. 2009, $131,448-449$.

(16) Ghosh, N.; Nayak, S.; Sahoo, A. K. J. Org. Chem. 2011, 76, 500511.

(17) Wang, D.; Cai, R.; Sharma, S.; Jirak, J.; Thummanapelli, S. K.; Akhmedov, N. G.; Zhang, H.; Liu, X.; Petersen, J. L.; Shi, X. J. Am. Chem. Soc. 2012, 134, 9012-9019.

(18) Wu, X.-F.; Bezier, D.; Darcel, C. Adv. Synth. Catal. 2009, 351, $367-370$.

(19) Cabrero-Antonino, J. R.; Leyva-Pérez, A.; Corma, A. Chem. Eur. J. 2012, 18, 11107-11114.

(20) Kanemitsu, H.; Uehara, K.; Fukuzumi, S.; Ogo, S. J. Am. Chem. Soc. 2008, 130, 17141-17147.

(21) Hirabayashi, T.; Okimoto, Y.; Saito, A.; Morita, M.; Sakaguchi, S.; Ishii, Y. Tetrahedron 2006, 62, 2231-2234.

(22) Tachinami, T.; Nishimura, T.; Ushimaru, R.; Noyori, R.; Naka, H. J. Am. Chem. Soc. 2013, 135, 50-53.

(23) Chen, Z.-W.; Ye, D.-N.; Qian, Y.-P.; Ye, M.; Liu, L.-X. Tetrahedron 2013, 69, 6116-6120.

(24) Thuong, M. B. T.; Mann, A.; Wagner, A. Chem. Commun. 2012, 48, 434-436.

(25) (a) Tsuchimoto, T.; Joya, T.; Shirakawa, E.; Kawakami, Y. Synlett 2000, 2000, 1777-1778. (b) Liang, S.; Hammond, G.; Xu, B. Chem. Commun. 2015, 51, 903-906.

(26) Olivi, N.; Thomas, E.; Peyrat, J.-F.; Alami, M.; Brion, J.-D. Synlett 2004, 2004, 2175-2179.

(27) Sun, C.-L.; Shi, Z.-J. Chem. Rev. 2014, 114, 9219-9280.

(28) Abitelli, E.; Protti, S.; Fagnoni, M.; Albini, A. J. Org. Chem. 2012, 77, 3501-3507.

(29) Protti, S.; Fagnoni, M.; Albini, A. Angew. Chem., Int. Ed. 2005, $44,5675-5678$.

(30) Bégué, J.-P.; Bonnet-Delpon, D.; Crousse, B. Synlett 2004, 2004, $18-29$.

(31) Noyce, D. S.; Matesich, S. M. A.; Peterson, P. E. J. Am. Chem. Soc. $1967,89,6225-6230$.

(32) Noyce, D. S.; Schiavelli, M. D. J. Am. Chem. Soc. 1968, 90, $1020-1022$.

(33) Allen, A. D.; Chiang, Y.; Kresge, A. J.; Tidwell, T. T. J. Org. Chem. 1982, 47, 775-779. 
(34) Lucchini, V.; Modena, G. J. Am. Chem. Soc. 1990, 112, 62916296.

(35) We tried to optimize the transition state structure for this protonation step. Unfortunately, the transition state optimization could not produce any converged structure. Nevertheless, we were able to obtain the converged structure for the vinyl carbocation intermediate in both solvents. Based on Hammond's postulate, we envisioned that the transition state information could be reflected by the intermediate. Therefore, we concluded that comparing energy differences between the intermediates in both solvents still revealed useful information.

NOTE ADDED AFTER ASAP PUBLICATION

Reference 25b was added on April 20, 2016. 